\title{
Pre-Service Primary Teachers' Attitudes towards Mathematics in an Australian University
}

\author{
Dilshara Hill1, Ayse Aysin Bilgin² \\ ${ }^{1}$ Department of Mathematics, Macquarie University, Sydney, Australia \\ ${ }^{2}$ Department of Statistics, Macquarie University, Sydney, Australia \\ Email: dilshara.hill@mq.edu.au
}

How to cite this paper: Hill, D., \& Bilgin, A. A. (2018). Pre-Service Primary Teachers' Attitudes towards Mathematics in an Australian University. Creative Education, 9, 597-614.

https://doi.org/10.4236/ce.2018.94042

Received: January 3, 2018

Accepted: April 14, 2018

Published: April 17, 2018

Copyright (c) 2018 by authors and Scientific Research Publishing Inc. This work is licensed under the Creative Commons Attribution International License (CC BY 4.0).

http://creativecommons.org/licenses/by/4.0/

(c) (i) Open Access

\begin{abstract}
Pre-service primary teachers are important people to shape future generations, as they will be the first face of mathematics a young child meets when he/she starts school. Since numerical literacy is becoming as important as literacy itself due to ease of data collection and ease of analysis of the data, it is important to educate the future generation and their teachers to be as effective as possible in their abilities to learn/teach mathematics. The research on pre-service teachers' mathematical anxiety and their attitudes towards mathematics show that the pre-service teacher typically has high levels of maths anxiety and that their attitude to mathematics makes a big difference to their learning during their studies at the university and then teaching mathematics to their young students. The purpose of this study was to investigate the relationship between previous (i.e. high school) mathematics study and attitudes toward mathematics. Our study showed that a high percentage of participants who studied mathematics in their final year at high school had a somewhat positive attitude toward mathematics.
\end{abstract}

\section{Keywords}

Attitudes toward Mathematics, Pre-Service Primary Teachers, Mathematics Education, STEM Education

\section{Introduction}

The study of pre-service teachers' attitudes to mathematics and mathematics teaching is a well-researched area (White, Way, Perry, \& Southwell, 2005-2006; Burton, 2012; Flegg, Mohammed, \& Trimmer, 2013). Literature documents 
many contributing factors to a pre-service teacher's attitude to mathematicsthe student's background (Grootenboer \& Hemmings, 2007), their beliefs and maths achievement (White, Way, Perry, \& Southwell, 2005), the role of maths anxiety (Gresham, 2010), their own self concept (Hackett \& Betz, 1989) and even gender (Cakiroglu \& Isiksa, 2009).

Previous research has shown that pre-service primary teachers tend to have a high level of mathematics anxiety, and an overwhelming majority show a negative attitude towards mathematics (Burton, 2012). Mathematics anxiety is particularly prevalent in those students studying to be pre-service primary teachers when compared to other university students studying mathematics (Brown, Westenkpw, \& Moyer-Packenham, 2011; Hadley \& Dorward, 2011).

White et al. cited from Fishbein \& Ajzen (1975) that "Attitudes are generally regarded as having been learnt. They predispose an individual to action that has some degree of consistency and can be evaluated as either negative or positive." (White, Way, Perry, \& Southwell, 2005-2006: p. 34). Following from their previous research, Ajzen \& Fishbein (1977) worked on analyzing a vast majority of articles on relationship between attitudes and behavior. They concluded their analysis by stating that "a person's attitude has a consistently strong relation with his or her behavior when it is directed at the same target and when it involves the same action". However, they also warned us that the measurements have to be clearly defined and targets identified before we can rely on these relationships. We therefore hypothesise that by studying the attitudes of pre-service primary teachers towards mathematics; we can gain some insight into their difficulties, which could be used to design courses to overcome them. If possible, then we might be able to help the students to achieve best learning outcomes in such courses. We argue that academics can structure their lectures and content to better engage their students, by being more aware of their students' background in mathematics and how teaching methods may affect the attitudes of their students.

White and collaborators' research (2005-2006) on pre-service primary teachers' attitudes to teaching mathematics, found reasonable evidence to support a positive relationship between the attitude of being insecure in one's mathematics teaching and the belief that this can be resolved by teaching mathematics in a way where the principal emphasis is on imparting routine procedures. It is not entirely clear from their research whether the teachers tended to focus on teaching routine procedures because they did not understand the underlying concepts themselves. If this is the case then there is a lot to do during university years.

Pre-service primary teachers are important people to shape future generations as they will be the teachers of the future and the first face of mathematics a young child meets when he/she starts school. Given that numerical literacy is becoming as important as literacy itself to support evidence-based decisions, it is important to educate the future generation of teachers to be as effective as possible in their abilities to teach mathematics. Therefore, the purpose of this study was to gain some insight into whether the pre-service teachers' demographics 
and their previous education play a role in determining their attitudes towards mathematics. If the factors can be identified then university educators could use strategies to influence pre-service teachers' attitudes and ability to teach mathematics. Furthermore, the findings from this study can influence current issues in Australia and around the world regarding STEM (Science, Technology, Engineering and Mathematics) objectives, namely encouraging more students to study STEM related courses during their university studies.

This research investigates the attitudes to mathematics that a pre-service primary teacher has, and in particular investigates the relationship between their previous high school mathematics study and the attitudes to mathematics. The participants are prospective teachers studying to become primary school teachers. This research was conducted in an Australian University on a cohort of these students who are pre-service primary teachers. We analysed the survey given to students and report on our findings.

\section{Background to Current Study}

Macquarie University is located in Sydney, Australia, and its campus is situated in one of the largest business and technology precincts in the southern hemisphere. With almost 40,000 students and 3000 staff (academic and professional), it offers programs across a wide range of disciplines including Arts, Business and Economics, Human Sciences, Science and Engineering, Health Sciences and Education (Macquarie University, 2015).

The students who are the focus of this study are primarily enrolled in the $\mathrm{Ba}$ chelor of Education programs or another Bachelor degree with a Diploma of Education. Many of them are studying to be Early Childhood or Primary School teachers. They usually come straight from high school into university, and they are usually very young (i.e. eighteen or nineteen years old).

The Mathematics Department at Macquarie University offers one mathematics unit, A View of Mathematics (MATH106 unit guide, 2013), to prospective primary teachers. This unit is one of two mathematics-based units that a student can take in their Education degree in our university. Therefore, it may be the only mathematics unit a primary or early childhood teacher would study during their higher education. The unit is designed by the Mathematics department specifically for pre-service Early Childhood and Primary School teachers, who hardly have any background in quantitative thinking, except their high school mathematics.

The lecturers of $A$ View of Mathematics go an extra mile to present material which is not part of a traditional mathematics program, (e.g.: Latin Squares), in a mathematical context with the aim to give students a positive experience in mathematics. The unit has a high level of support (more resources are allocated) compared to other mathematics units at Macquarie University. The extra resources include using technology such as well-developed presentations and discussion boards, as well as the presence of the Mathematics Student Support Of- 
ficer who constantly monitors and contacts students who start failing to engage with the unit (i.e. students who do not turn up to tutorials or fail to submit an assessment task). In other words, students who might be at academic risk of failure are warned before they actually fail the unit. These warnings enable to increase the number of students seeking help to learn and therefore decrease the number of students who fail the unit. The unit is available both internally (face-to-face on campus) and externally with three on-campus sessions scheduled during a semester, in weeks 4,8 and 12 (usually on a Saturday between 10 am and $5 \mathrm{pm}$ ).

$A$ View of Mathematics is different to standard entry-level mathematics units such that it covers non-standard topics such as Tilings, Platonic Solids and Perspective Drawings. It also contains content that students can use when they start teaching themselves such as Fractions, Divisibility and Place Value. The unit is assessed with regular assessments throughout the semester consisting of weekly quizzes, three assignments and a final exam (MATH106 unit guide, 2013). While it is considered quite challenging by the majority of students who take this unit, the students who engage with it have found it to give them a positive experience in mathematics.

\section{Survey and Participants}

Macquarie University, the Faculty of Science and Engineering, Human Research Ethics Sub-Committee approved the study (Reference Number 5201300483).A paper-based survey was conducted of students in the 2013 cohort $(\mathrm{n}=278)$ of $A$ View of Mathematics, where the teaching took place on campus (internal offering). The response rate was $50 \%(\mathrm{n}=139)$ which is very high compared to other surveys administered at Macquarie University. Macquarie University encourages paper-based surveys wherever possible to increase the response rate by students. University's teaching evaluation for development service (TEDS) reports that over the past 3 years, only $4 \%$ of 2359 online surveys had a response rate which deemed them (statistically) valid. They consider a survey to be valid if the minimum response rate is $25 \%$ where the target population has 100 or more students (Macquarie University, TEDS, 2015). The response rate to our study well exceeded this minimum.

The survey was administered before the first MATH106 lecture began, before students had gained exposure to studying mathematics at university. The survey had four parts. The first part included questions relevant to demographics of the participants, namely their gender, age group and the level of mathematics studied prior to beginning university. In the second part of the survey, participants were asked to agree or disagree to ten statements about mathematics on a five point Likert scale ( $1=$ strongly disagree to $5=$ strongly agree) and this was used to investigate their attitudes to mathematics. We also asked participants to choose relevant words to describe how they feel about doing mathematics in this section by providing them a list of feeling words such as anxious, excited, nerv- 
ous and enthusiastic. Part three of the survey was designed mainly as open-ended questions to understand participants negative experiences with mathematics. Finally, part four was similar to part three where we asked about positive experiences with mathematics. We estimated that the survey would take 10 minutes to complete.

The students' responses to their highest level of Mathematics study they had undertaken prior to studying MATH106 covered three areas of the New South Wales (one of the states in Australia) high school mathematics syllabus. The first, non-Higher School Certificate (HSC) mathematics consisted mostly of those students who had done Year 10 mathematics or below, which comprises mathematics in junior years of high school and covers topics such as Whole Numbers, Fractions, Areas and Volumes. There were a small number of students (nine) who had done year 11 mathematics and then dropped mathematics in their final year at high school who were also included in this group. The second was Year 12 HSC General Mathematics, which is a subject available to students who have completed year 10 mathematics and covers concepts such as Measurement, Algebra and Statistics. The third group was Year 122 unit HSC Mathematics or higher, which covers topics such as Functions, Trigonometry and Calculus (BOSTES, 2014).

The students' Mathematics Level was grouped into two categories-non-HSC mathematics (comprising of those who had done year 11 mathematics or below) and HSC mathematics (comprising of those who had done mathematics in their final year at high school, including Year 12 General Mathematics and Year 122 unit HSC Mathematics or higher). There were very few students in the cohort who had studied the highest levels of mathematics at high school with only three who had completed Year 12 HSC Extension 1 (3 unit) Mathematics and one student had completed Year 12 HSC Extension 2 (4 unit) Mathematics.

\section{Data Analysis}

The students' responses to ten statements about their attitudes to mathematics were the core of the data analysis (Table 1). Some statements were worded as positive statements ( 7 out of 10) and others as negative ones ( 3 out of 10). An example of positive statement from the survey is "I find maths interesting" and a negative statement is "I struggle with maths". For the purpose of having a consistent analysis of attitudes we reversed responses to negative statements before the analysis.

Excellent internal consistency for ten statements (Table 1) about participants' attitudes to mathematics was demonstrated in the present study (Cronbach's $\alpha=$ 0.908). The analysis of parts three and four will be written as a separate paper.

A description of the attitudes for the cohort was investigated by looking at the distribution of the percentages of responses that agreed or disagreed with each attitude statement, as well as calculating means and standard errors of the means for each statement. 
Table 1. Descriptive statistics for attitudes towards mathematics statements.

\begin{tabular}{cccc}
\hline \multirow{2}{*}{ Attitudes Towards Mathematics } & & \multicolumn{2}{c}{ Descriptive Statistics } \\
\cline { 3 - 4 } I find Mathematics interesting & At1 & 3.1 & 0.09 \\
I enjoy solving problems & At2 & 3.1 & 0.09 \\
I do not struggle with Mathematics & At3 & 2.7 & 0.10 \\
New Maths concepts are usually easy to understand & At4 & 2.7 & 0.08 \\
Mathematics can be fun & At5 & 3.4 & 0.08 \\
Everyone can succeed at Mathematics & At6 & 3.3 & 0.08 \\
I can grasp mathematical concepts easily & At7 & 3.3 & 0.10 \\
I attempt mathematics, even if it is hard & At8 & 3.5 & 0.10 \\
I enjoyed mathematics at school & At9 & 3.0 & 0.11 \\
I feel that I was successful in mathematics & At10 & 2.9 & 0.10 \\
\hline
\end{tabular}

We were interested to see whether there was a relationship between studying mathematics during high school or not and the responses to statements about attitudes to mathematics. Due to small numbers in the extreme categories (Strongly agree or strongly disagree), participants' responses to the statements were grouped into three categories-Agree (containing Strongly Agree and Agree responses), Neutral and Disagree (containing Strongly Disagree and Disagree responses) before statistical analysis. The relationships between previous Mathematics Level (whether students studied mathematics during the last two years of high school or not) and Attitudes to mathematics were investigated using Chi-Squared Tests. When the assumptions for the Chi-Squared test failed, we used Fisher's Exact Test. The statistical significance level is 0.05 .

IBM SPSS Statistics Version 24 is used for data analysis (IBM, 2016).

\section{Results}

\subsection{Demographics of the Participants}

There was not an even spread of gender with $87 \%$ of MATH106 students surveyed being female. However, this is not surprising or interesting since there are not many male students in the Bachelor of Education degrees across Australian universities and in Australian teachers' workforce, especially for primary schools (Richardson \& Watt, 2005; McGrath \& Bergen, 2017). The distribution of ages of the pre-service primary teachers who responded to the survey showed that $71 \%$ of them were between seventeen and twenty years of age; $22 \%$ were between twenty-one and twenty-nine years of age and $7 \%$ were thirty years of age or older.

We found that almost a quarter (24\%) of the students reported that they did not study year 12 HSC mathematics, while slightly more than half (54\%) did year 12 General Mathematics (non calculus based mathematics course). Only 
$17 \%$ had done year 122 unit HSC Mathematics or higher which are the high school calculus based courses. We consider that the students who had done no HSC mathematics to have little or no mathematics in their background before commencing MATH106.

Fisher's Exact Test revealed no significant relationship between studying Year 12 HSC mathematics and gender $(p=0.75)$. However we found that younger participants (17 - 20 years old) were more likely to study Year 12 HSC mathematics (83\%), compared to $21-29$ years old (57\%) and 30 years or older $(50 \%)$ participants (Fisher's Exact Test $p=0.004$ ).

\subsection{Attitudes toward Mathematics}

There was a high proportion of 'Neutral' responses. At least $31 \%$ in eight out of ten statements, responses were neutral and $20 \%$ in the remaining statements (Figure 1).

We found certain responses had a similar pattern as shown in Table 1 and Figure 1. As expected, "I do not struggle with Mathematics" (At3), "New mathematical concepts are usually easy to understand" (At4) and "I feel that I was successful in mathematics" (At10) had the lowest means, while surprisingly "I attempt mathematics, even if it is hard" (At8) and "Mathematics can be fun" (At5) had the highest means (Table 1).

It is clear that more students were disagreeing than agreeing to the positive statements made about doing mathematics (Figure 1). Four out of ten (42\%) participants disagreed with the statement "I do not struggle with mathematics" (At3) while three out of ten agreed (27\%), and 37\% disagreed with the statement "New mathematical concepts are easy to understand" (At4) while 19\% agreed. In Figure 1, statements At1, At2, At5, At6, At7 and At8 are about the subject of

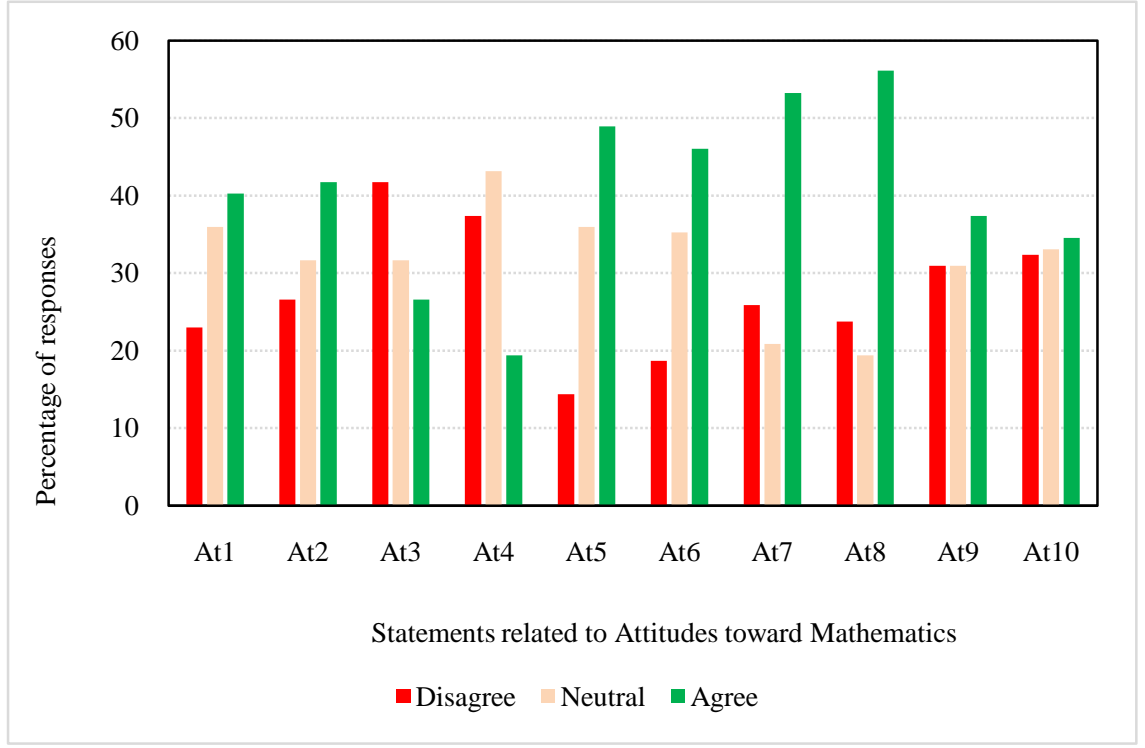

Figure 1. Responses to Statements about Attitudes Toward Mathematics ${ }^{a}$, ${ }^{\text {a The state- }}$ ments are listed in Table 1. 
mathematics. There is generally a more positive attitude to the subject of mathematics, with agreement to the positive statements all being above $40 \%$. However in particular we would note that over one quarter of students disagreed with the statements "I enjoy solving problems" (At2) and "I can grasp mathematical concepts easily" (At7). The attitudes to past success in mathematics were investigated by two statements; "I enjoyed mathematics at school" (At9) and "I feel that I was successful in mathematics" (At10) (Figure 1). While there is not much difference between disagree, neutral and agree, we see slightly more agreement to positive statements about past enjoyment of and success in mathematics.

\subsection{Previous Study and Attitudes toward Mathematics}

We investigated the relationship between whether the students studied Year 12 HSC mathematics or not and their attitudes toward mathematics at university. We found statistically significant associations between seven out of ten attitude statements (At1, At3, At5, At7, At8, At9 and At10) in the survey and prior study of mathematics (no Year 12 HSC mathematics or Year 12 HSC Mathematics).

The association between whether participants studied mathematics during their Year 12 or not and whether participants found mathematics interesting (At1) was statistically significant $\left(\chi^{2}=18.9, \mathrm{df}=2, p<0.001\right)$, where $91 \%$ of participants who agreed to the statement studied mathematics, and the remaining did not. The observed number of counts for disagreeing to the statement (At1) were higher than expected for no Year 12 mathematics participants while they were lower than expected for Year 12 mathematics participants. Similarly, the observed counts for agreeing to the statement were lower than expected for the no mathematics participants and higher than expected for Year 12 mathematics participants.

The association between whether participants studied mathematics during their Year 12 and whether participants enjoy solving problems (At2) was not statistically significant $\left(\chi^{2}=4.6, \mathrm{df}=2, p=0.1\right)$, where $82 \%$ of participants who agreed to the statement (At2) studied mathematics in their final year at high school.

Our Chi-square test revealed that the percentage of participants disagreeing to "I do not struggle with mathematics" (At3) significantly differed by their previous mathematics level of study $\left(\chi^{2}=10.1, \mathrm{df}=2, p=0.007\right)$, while one-third of the participants with Year 12 HSC mathematics were disagreeing to this statement, two-thirds of the participants with no Year 12 HSC mathematics disagreed. This indicates that Year 12 HSC mathematics might be beneficial to pre-service primary teachers to overcome their difficulties with mathematics.

The association between whether participants found new mathematical concepts are easy to understand (At4) and whether they studied mathematics during Year 12 , was not statistically significant $\left(\chi^{2}=3.5, \mathrm{df}=2, p=0.17\right)$. In addition, in both groups there were more participants disagreeing than agreeing to the statement (At4). This means that even if the pre-service primary teachers study 
Year 12 HSC mathematics, they might still find new mathematical concepts hard to understand.

Fisher's Exact Test revealed a significant relationship between studying Year 12 HSC mathematics and whether mathematics is considered to be fun ( $p=$ 0.023). Majority of participants (85\%) who agreed with the statement "Mathematics can be fun" (At5) did mathematics in their final year at high school. In addition, while more than half of the participants (56\%) who studied mathematics at high school were agreeing with the statement (At5), only one-third of the participants who did not study mathematics were agreeing (31\%).

Close to half of the participants in both Year 12 HSC mathematics (46\%) and no Year 12 HSC mathematics (42\%) agreed to the statement "Everyone can succeed at Mathematics" (At6), the association between their responses to the statement (At6) and whether they studied mathematics or not was not statistically significant $\left(\chi^{2}=0.82, \mathrm{df}=2, p=0.67\right)$.

The association between whether participants studied mathematics during Year 12 or not and whether participants felt they could grasp mathematical concepts easily (At7) was statistically significant $\left(\chi^{2}=13.1, \mathrm{df}=2, p=0.001\right)$, where $86 \%$ of participants who agreed to the statement studied mathematics, and the remaining did not. The observed number of counts for disagreeing to the statement (At7) were higher than expected for no Year 12 mathematics participants while they were lower than expected for Year 12 mathematics participants. Similarly, the observed counts for agreeing to the statement were lower than expected for no mathematics participants and higher than expected for Year 12 mathematics participants.

Our Chi-square test revealed that the percentage of participants disagreeing to "I don't attempt mathematics because it's too hard" (At8) significantly differed by their previous mathematics study $\left(\chi^{2}=12.3, \mathrm{df}=2, p=0.002\right)$. While two-thirds of the participants with Year 12 HSC mathematics were disagreeing to this statement (At8), only one-third of the participants with no Year 12 HSC mathematics disagreed. This indicates that Year 12 HSC mathematics might help pre-service primary teachers to develop resilience and positive attitude towards mathematics. The majority of participants $(85 \%)$ who disagreed with this statement (At8) studied mathematics in their final year at high school. Please note that we reverse coded this statement for graphical displays as "I attempt mathematics even it is hard" (At8).

The association between whether participants studied mathematics during Year 12 or not and whether they enjoyed mathematics at school (At9) was statistically significant $\left(\chi^{2}=25.8, \mathrm{df}=2, p<0.001\right)$, where $90 \%$ of participants who agreed to the statement studied mathematics. The observed number of counts for disagreeing to the statement (At9) were twice as high as expected for no Year 12 mathematics participants while they were lower than expected for Year 12 mathematics participants. Similarly, the observed counts for agreeing to the statement were lower than expected for no Year 12 mathematics participants 
and higher than expected for Year 12 mathematics participants. In addition, while close to half of the participants (44\%) who studied mathematics at high school were agreeing with the statement (At8), a very small minority (15\%) of the participants who did not study mathematics were agreeing. It is not clear here whether participants did not study mathematics at school because they did not enjoy it or they did not enjoy it because they did not study it at school. It is like chicken and egg problem, which comes first is not clear.

Our Chi-square test revealed that the percentage of participants agreeing or disagreeing to "I feel that I was successful in mathematics" (At10) significantly differed by their previous mathematics level of study $\left(\chi^{2}=21.8, \mathrm{df}=2, p<\right.$ $0.001)$. While more than six out of ten participants (64\%) with no Year 12 HSC mathematics were disagreeing to this statement, only two out of ten participants (22\%) with Year 12 HSC mathematics disagreed. The majority of participants (93\%) who agreed with this statement (At10) studied mathematics in their final year at high school.

From the results, it is clear that a high percentage of students who did mathematics in their final year at high school had a somewhat positive attitude toward mathematics. However, mathematics study at high school did not make them believe that new mathematical concepts can be understood easily (At4), everyone can succeed at mathematics (At6) and they can enjoy solving problems (At2). Nevertheless, it made them believe that mathematics is interesting (At1), mathematics can be fun (At5), they could grasp mathematical concepts easily (At7), they enjoyed studying mathematics at school (At9), they felt that they were successful in mathematics (At10) and it gave them confidence to attempt mathematics even if they think it is hard (At8). More of the participants with Year 12 HSC mathematics disagreed that they struggled with mathematics (At3) than no Year 12 HSC mathematics participants.

\subsection{Gender and Attitudes toward Mathematics}

There were no statistically significant results for the gender and attitudes toward mathematics; however, the distribution of responses by the participants had a clear pattern toward favoring positive attitudes by male participants (Table 2). For example, while $80 \%$ of the male participants were agreeing that they can grasp mathematical concepts easily (At7) and they attempt mathematics even if it is hard (At8), just above $50 \%$ of the female participants were agreeing to these statements. On the other hand, two out of five female participants were disagreeing that they do not struggle with mathematics (At3) while only one out of five male participants disagreeing. Similarly, while $35 \%$ of female participants were disagreeing that they feel that they were successful in mathematics (At10), only $13 \%$ of male participants were disagreeing to the same statement.

\subsection{Age and Attitudes to Mathematics}

There were only ten participants in the 30 years and older age group. For the investigation of the associations between age and attitudes toward mathematics, 
we collapsed the age groups into two categories, $17-20$ years $(n=98)$ and 21 years and older $(n=41)$ so that assumptions for the statistical tests are satisfied. The percentages of agreements along with statistics are presented in Table 3.

Table 2. The associations between gender and attitudes toward mathematics.

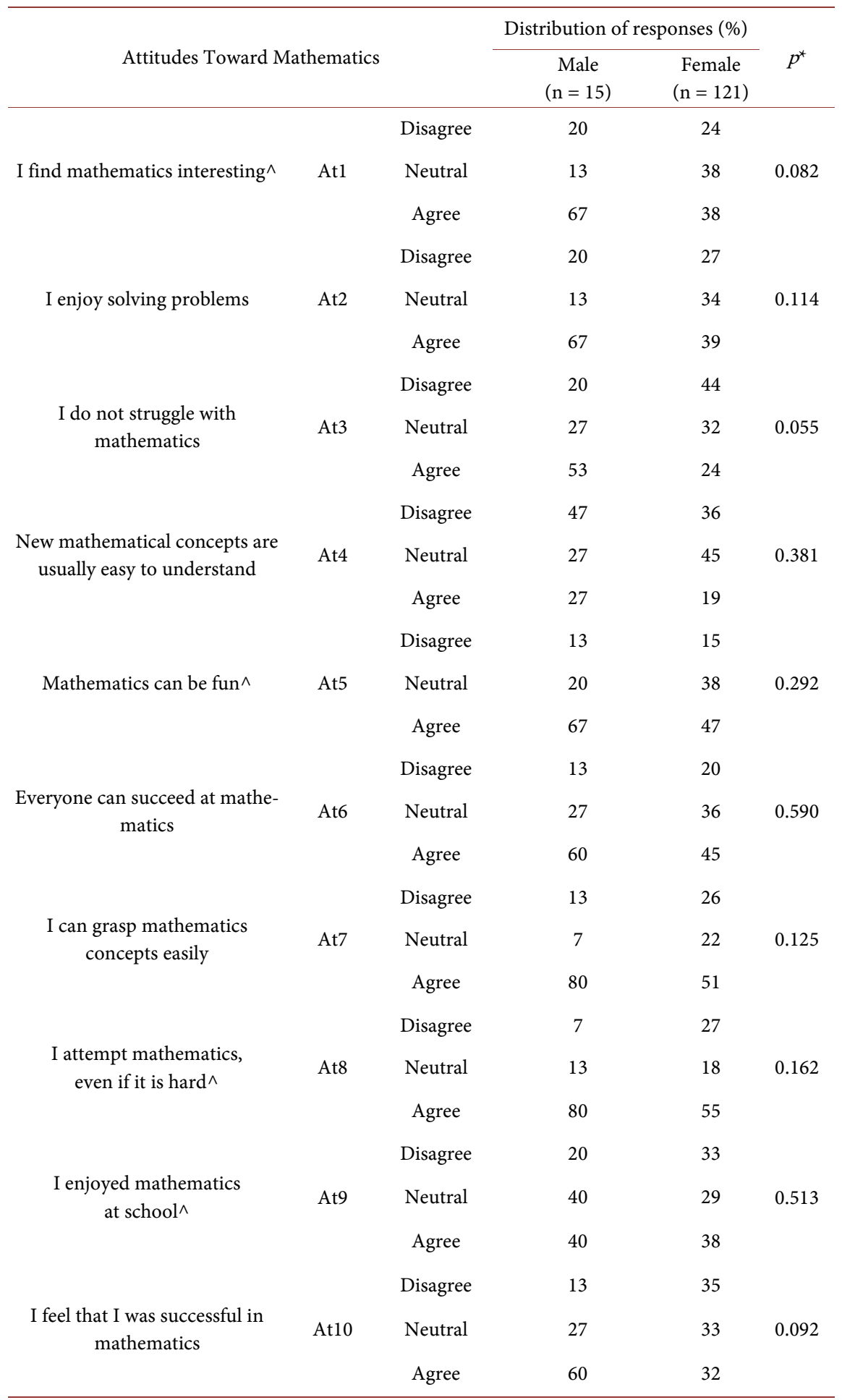

${ }^{\star}$ Fisher's Exact Test is used for testing unless otherwise specified. ^ There were 120 female responses for this statement. 
Table 3. The associations between age and attitudes toward mathematics.

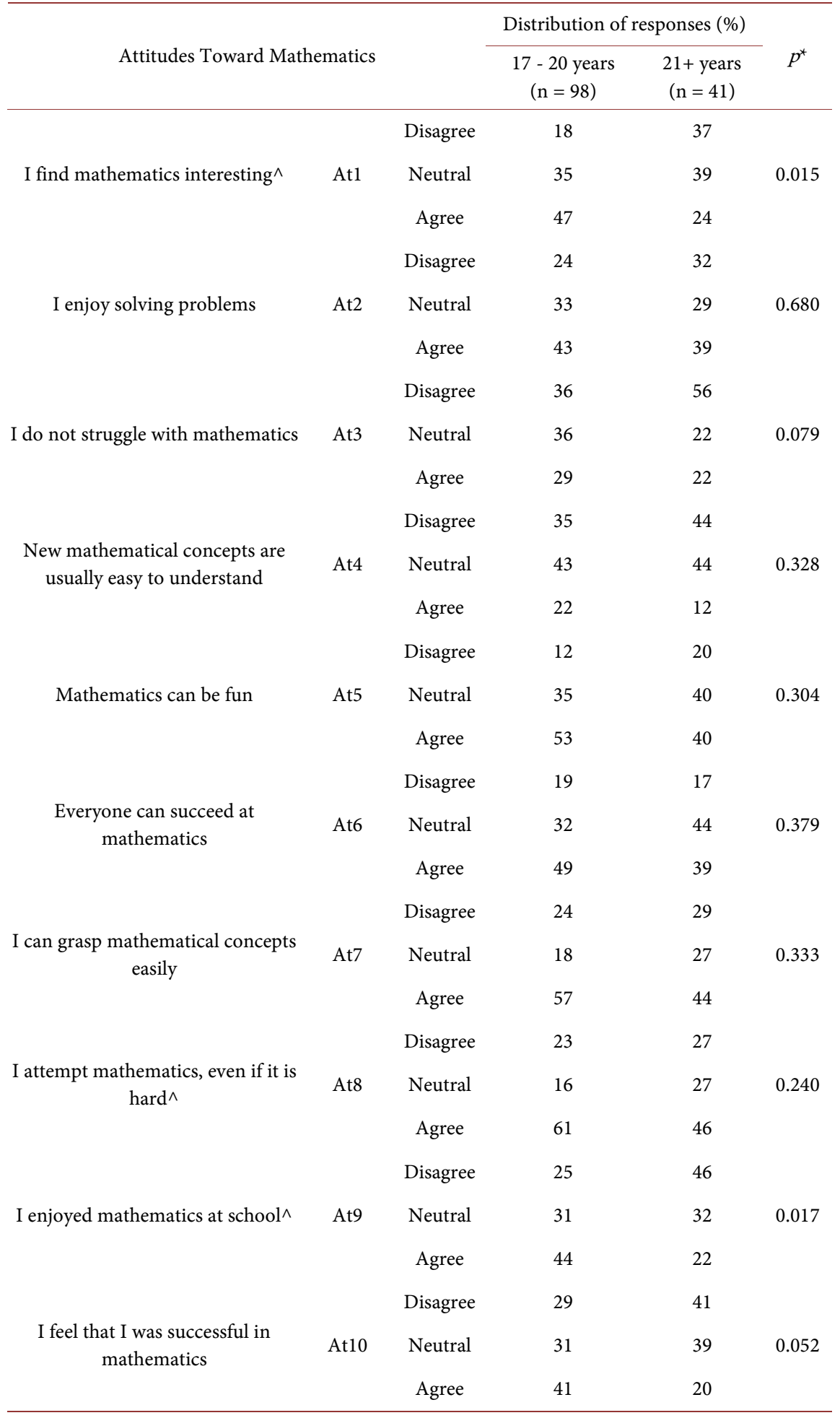

${ }^{*}$ Chi-square test. $\wedge$ There were 97 younger participants responses for this statement.

Significantly higher percentage of younger age group (17 - 20 year olds) participants (47\% compared to $24 \%$ in the older age group) found mathematics interesting (At1) $\left(\chi^{2}=8.41, \mathrm{df}=2, p=0.015\right)$. 
Our Chi-square test revealed that the percentage of participants' agreement to "I enjoy solving problems" (At2) did not significantly differ by their age $\left(\chi^{2}=\right.$ $10.1, \mathrm{df}=2, p=0.68)$. For both age groups, more than one-third of participants agreed to this statement (At2) while one-third or less disagreed.

Our Chi-square test revealed that the percentage of participants' agreement to "I do not struggle with mathematics" (At3) did not significantly differ by their age $\left(\chi^{2}=5.1, \mathrm{df}=2, p=0.079\right)$. However, more than half of the older age group (56\%) were disagreeing to this statement compared to $36 \%$ of younger age group (17 - 20 year olds).

Our Chi-square test revealed that the percentage of participants' agreement to "New mathematical concepts are usually easy to understand" (At4) did not significantly differ by their age $\left(\chi^{2}=2.2, \mathrm{df}=2, p=0.328\right)$. More participants in both age groups were disagreeing to the statement (At4), however the percentage of participants in the younger age group who agreed to this statement $(22 \%)$ were almost twice as much as in the older age group (12\%). This might mean that older participants need more help to learn new mathematical concepts.

The percentage of agreement to "Mathematics can be fun" (At5) did not differ by age $\left(\chi^{2}=2.4, \mathrm{df}=2, p=304\right)$, however more than half of the younger participants $(53 \%)$ agreed to this statement while only $40 \%$ of older participants were agreeing.

There was a higher percentage of participants agreeing to the statement 'Everyone can succeed at mathematics' (At6) in both age groups, and there was no statistically significant difference between them $\left(\chi^{2}=1.9, \mathrm{df}=2, p=0.379\right)$. Similarly, there were a higher percentage of participants agreeing to the statements "I can grasp mathematical concepts easily" (At7) and "I attempt mathematics, even it is hard" (At8) in both age groups, and there were no statistically significant differences $\left(\chi^{2}=2.2, \mathrm{df}=2, p=0.333\right.$ and $\chi^{2}=2.8, \mathrm{df}=2, p=0.24$, respectively).

A significantly higher percentage of younger age group (17 - 20 year olds) participants ( $44 \%$ compared to $22 \%$ in older group) agreed that they enjoyed mathematics at school $\left(\chi^{2}=8.2, \mathrm{df}=2, p=0.017\right)$.

There was a higher percentage of participants agreeing to the statement "I feel that I was successful in mathematics" (At10) in the younger age group (41\% compared to $20 \%$ in the older age group), but there was no statistically significant difference between them $\left(\chi^{2}=5.9, \mathrm{df}=2, p=0.052\right)$.

\subsection{Previous Experience and Feelings about Mathematics}

More than one-third of the participants had mixed feelings (36\%) about mathematics. One-third (32\%) had positive feelings about mathematics while another one-third had negative feelings (30\%) about mathematics (Table 4).

Although more than half of the participants $(n=63)$ stated having a good experience $(53 \%)$ with mathematics, only half of the participants with a good experience had positive feelings about mathematics $(n=31)$ while the remaining 
Table 4. The association between previous experience and feelings about mathematics.

\begin{tabular}{ccccc}
\hline \multirow{2}{*}{ Feelings about Mathematics } & \multicolumn{3}{c}{ Previous Experience in Mathematics* } \\
\cline { 2 - 5 } & Positive & Negative & Both & All participants \\
\hline Positive & $32(51 \%)$ & $0(0 \%)$ & $6(26 \%)$ & $38(32 \%)$ \\
Mixed & $16(25 \%)$ & $8(24 \%)$ & $12(52 \%)$ & $43(36 \%)$ \\
Neutral or No experience & $1(2 \%)$ & $1(3 \%)$ & $0(0 \%)$ & $36(30 \%)$ \\
Negative & $14(22 \%)$ & $14(73 \%)$ & $5(22 \%)$ & $2(2 \%)$ \\
All participants & $63(53 \%)$ & $33(28 \%)$ & $23(19 \%)$ & $119(100 \%)$ \\
\hline
\end{tabular}

*The numbers represent the number of participants (n) and the percentages within each column.

half was split between negative feelings and mixed feelings (Table 4). On the other hand, a quarter of the participants $(\mathrm{n}=33)$ stated having a bad experience with mathematics. None of the participants with a bad experience had good feelings about mathematics and the vast majority (73\%) had bad feelings about mathematics while $24 \%$ had mixed feelings about mathematics (3\% did not answer this question).

A small number of participants (19\%) had both positive and negative experiences with mathematics and half of these participants had mixed feelings about it while the remaining half was split between positive and negative feelings about mathematics. Further analysis regarding the previous experiences in mathematics and feelings about mathematics will be written in a follow-up paper.

\section{Conclusion}

The result of this study shows that studying Mathematics prior to university in the final year of high school was significantly related to pre-service teachers' attitudes towards mathematics. We found evidence that the proportion of students agreeing to the positive attitudes towards Mathematics was higher for the students who studied Mathematics during their final year at high school. While neither age nor gender showed statistically significant results, we could see a clear pattern of more positive attitudes by male participants, and responses seemed to indicate that older participants may need more assistance in learning new mathematical concepts.

Our results also showed that the majority of respondents did not agree with the ten positively worded statements about mathematics (less than $50 \%$ agreement). The only two exceptions to this where we found more agreement than disagreement were to the statements "I can grasp mathematical concepts easily" and "I attempt mathematics even if it's hard". Therefore we can conclude that almost one quarter of our cohort who did not do mathematics at high school may not have entirely positive or realistic attitudes to mathematics. This phenomenon has been highlighted in other research and seems to be a common occurrence amongst pre-service primary teachers (Burton, 2012).

This research has implications for how academics involved in the mathemati- 
cal education of pre-service primary teachers develop courses, present content and engage with their students. Although university educators could not directly influence whether their students choose to study Mathematics in their final year of high school, they can tailor their university courses to influence their students' attitudes towards Mathematics. It must be expected that some negative attitudes of students will have to be addressed. These important considerations need to be taken into account so that pre-service primary teachers can have a positive and successful experience in mathematics education, and in turn give their own future students a positive experience in mathematics.

This research raises important questions about prerequisite knowledge of mathematics in pre-service primary teachers. An obvious solution to increase pre-service primary teachers' positive attitudes towards Mathematics, is to include a prerequisite of undertaking mathematics in the final year of high school for students who intend to study primary teaching. In Australia this would correspond to a prerequisite of Year 12 Mathematics. If implemented, this requirement might press the importance of mathematics in education at all levels and also address the issue of negative attitudes in pre-service primary teachers. We hypothesise that those students who have a fully negative attitude to mathematics and do not want to undertake mathematics in Year 12 would not be the ideal candidate for a primary teaching career. We acknowledge that the inclusion of a prerequisite of Mathematics at Year 12 might not be easily implemented due to shortages of qualified high school Mathematics teachers, and note that even now some high schools are employing science teachers to teach Mathematics to their students (Weldon, 2015).

However we make the recommendation of having a prerequisite requirement of the study of mathematics in the final year of high school be implemented for those students who intend to train as primary school teachers, for the following reasons.

Currently in Australia, strategies are being developed to include a plan for STEM in education throughout schools (Education Council, 2015; Prinsley \& Johnston, 2015; Bilgin, Date-Huxtable, Coady, Geiger, Cavanagh, Mulligan, \& Petocz, 2017). The Education Council has put forward a National STEM School Education Strategy 2016-2026 (Education Council, 2015) which lists five areas for national action. Namely

1) Increasing student STEM ability, engagement, participation and aspiration.

2) Increasing teacher capacity and STEM teaching quality.

3) Supporting STEM education opportunities within school systems.

4) Facilitating effective partnerships with tertiary education providers, business and industry.

5) Building a strong evidence base.

This research addresses all five of these STEM objectives by highlighting the need for prospective teachers to be well prepared to teach mathematics, and also promote positive attitudes towards mathematics in their own teaching career, thereby engaging their own students and supporting STEM opportunities. Our 
recommendation might help to achieve these aims.

The Chief Scientist, Professor Ian Chubb, responded to the Australian Government's consultation paper Vision for a Science Nation by stating, 'What is required are positive learning experiences in mathematics and science, provided by capable teachers' (Australian College of Educators, 2015: p. 1). While the Chief Scientist supports the government's proposal for a specialisation pathway for primary teachers, we argue that to be able to achieve positive learning experiences in Mathematics, one needs to have studied Mathematics throughout high school. To allow all primary teachers to have some mathematics in their background and therefore promote positive attitudes and learning outcomes in mathematics, a reasonable recommendation would be implementing the study of mathematics in the final year of high school as a prerequisite for pre-service primary teachers' education.

We are aware that this study is conducted on only one cohort of students and in only one university which might make our results less generalisable. We also know that because of the anonymity of the respondents, we were unable to report on students' success or failure of MATH106. Further research on how pre-service teachers' past experiences in mathematics influence their attitudes towards Mathematics at University is currently being conducted and we hope to include collaborators from other universities within Australia and may be from other countries.

\section{Acknowledgements}

Thank you to Garry Lawson-Mathematics Teaching and Learning Support Officer at Macquarie University, who assisted in gathering the data used in this research. This paper would not have been possible without the students in MATH106 who participated in the survey.

\section{References}

Ajzen, I., \& Fishbein, M. (1977). Attitude-Behavior Relations: A Theoretical Analysis and Review of Empirical Research. Psychological Bulletin, 84, 888-918. https://doi.org/10.1037/0033-2909.84.5.888

Australian College of Educators (ACE). (2015). Response to the Australian Government's Consultation Paper: Vision for a Science Nation. Responding to Science, Technology, Engineering and Mathematics: Australia's Future. Australian College of Educators. https://www.austcolled.com.au/policy/submissions/

Bilgin, A. B. B., Date-Huxtable, E., Coady, C., Geiger, V., Cavanagh, M., Mulligan, J., \& Petocz, P. (2017). Opening Real Science: Evaluation of an Online Module on Statistical Literacy by Pre-Service Primary Teachers. Statistics Education Research Journal-Special Edition on Statistical Literacy, 16, 120-138.

BOSTES (2014). HSC Course Descriptions-Mathematics. NSW, Australia. http://www.boardofstudies.nsw.edu.au/syllabus_hsc/course-descriptions/mathematics. $\underline{\text { html\#mathematics }}$

Brown, A., Westenskow, A., \& Moyer-Packenham, P. (2011). Elementary Pre-Service Teachers: Can They Experience Mathematics Teaching Anxiety without Having Ma- 
thematics Anxiety? Issues in the Undergraduate Mathematics Preparation of School Teacher: The Journal, 5, 1-14.

http://www.k-12prep.math.ttu.edu/journal/5.attributes/brown01/article.pdf

Burton, M. (2012). What Is Math? Exploring the Perception of Elementary Pre-Service Teachers. Issues in the Undergraduate Mathematics Preparation of School Teacher: The Journal, 5, 1-17. http://www.k-12prep.math.ttu.edu/journal/5.attributes/burton02/article.pdf

Cakiroglu, E., \& Isiksa, M. (2009). Preservice Elementary Teachers' Attitudes and Self-Efficacy Beliefs toward Mathematics. Education and Science, 34, 132-139.

Education Council (2015). National Science, Technology, Engineering and Mathematics (STEM) School Education Strategy: 2016-2026.

http://www.educationcouncil.edu.au/site/DefaultSite/filesystem/documents/National\% 20STEM\%20School\%20Education\%20Strategy.pdf

Fishbein, M., \& Ajzen, I. (1975). Belief, Attitude, Intention and Behavior: An Introduction to Theory and Research. Reading, MA: Addison-Wesley.

Flegg, N., Mohamed, K., \& Trimmer, K. (2013). Synthesising the Literature Concerning Math Anxiety to Inform a Project on Pre-Service Teacher Retention Rates. In 3rd Advancing the STEM Agenda Conference. https://eprints.usq.edu.au/23618/

Gresham, G. (2010). A Study Exploring Exceptional Education Preservice Teachers' Mathematics Anxiety. Issues in the Undergraduate Mathematics Preparation of School Teachers: The Journal, 4, 1-14 http://www.k-12prep.math.ttu.edu/journal/4.curriculum/gresham01/article.pdf

Grootenboer, P., \& Hemmings, B. (2007). Mathematical Performance and the Role Played by Affective and Background Factors. Mathematics Education Research Journal, 19, 3-20. https://doi.org/10.1007/BF03217459

Hackett, G., \& Betz, N. (1989). An Exploration of the Mathematics Self-Efficacy/Mathematics Performance Correspondence. Journal for Research in Mathematics Education, 20, 261-273. https://doi.org/10.2307/749515

Hadley, K., \& Dorward, J. (2011). The Relationship among Elementary Teachers' Mathematics Anxiety, Mathematics Instructional Practices, and Student Mathematics Achievement. Journal of Curriculum and Instruction, 5, 27-44. https://doi.org/10.3776/joci.2011.v5n2p27-44

IBM Corp (2016). IBM SPSS Statistics for Windows, Version 24.0. Armonk, NY: IBM Corp.

Macquarie University (2015). Engaging the World Macquarie University in Profile.

Macquarie University, TEDS (2015). Teaching Evaluation and TEDS. https://staff.mq.edu.au/teaching/evaluation/surveys/get_valid_survey/

MATH 106 Unit Guide (2013). http://unitguides.mq.edu.au/unit_offerings/8071/unit_guide/print.pdf

McGrath, K. F., \& Van Bergen, P. (2017). Are Male Teachers Headed for Extinction? The 50-Year Decline of Male Teachers in Australia. Economics of Education Review, 50, 159-167. https://doi.org/10.1016/j.econedurev.2017.08.003

Prinsley, R., \& Johnston, E. (2015). Transforming STEM Teaching in Australian Primary Schools: Everybody's Business. Office of Chief Scientist Publications. http://www.chiefscientist.gov.au/wp-content/uploads/Transforming-STEM-teaching_F INAL.pdf

Richardson, P., \& Watt, H. (2005). "I've Decided to Become a Teacher": Influences on Career Change. Teaching and Teacher Education, 21, 475-489. 
https://doi.org/10.1016/j.tate.2005.03.007

Weldon, P. (2015). The Teacher Workforce in Australia: Supply, Demand and Data Issues. Australian Council for Educational Research. http://research.acer.edu.au/cgi/viewcontent.cgi?article=1001\&context=policyinsights

White, A., Way, J., Perry, B., \& Southwell, B. (2005-2006). Mathematical Attitudes, Beliefs and Achievement in Primary Pre-Service Mathematics Teacher Education. Mathemat ics Teacher Education and Development, 7, 33-52. 